\title{
Trihalomethane Formation Potential Due to Anthropogenic Sources in Surface Water
}

\author{
NIDHI DIXIT MISHRA and SATISH CHANDRA DIXIT* \\ Post-graduate Department of Chemistry, D.B.S. College, Kanpur-208006, India \\ satishdixit1@gmail.com
}

Received 10 September 2014 / Accepted 25 September 2014

\begin{abstract}
To study the formation potential of trihalomethanens (THMs) due to anthropogenic sources and effect of various precursors on the potential of THM formation, surface raw water samples were collected from Ganga Barrage Water Treatment Plant, Kanpur (India) from January to June 2009. The concentration of THMs and THMFP (Trihalomethane formation potential) at different chlorine dosages were below the WHO GV. THMFP values in May and June were found to be three times higher than those in January. Chloroform levels were found higher than DBCM (dibromochloromethane), DCBM (dichlorobromomethane) and BF (bromoform) in all the seasons. The seasonal variation of chloroform concentrations reported the level lower than WHO GV. THM formation rate was found to be very fast in first $24 \mathrm{~h}$ compared to that of exceeding reaction time. The higher the reaction time leads to the higher THM concentrations which was very prominent at higher chlorine dosages. Values of THMFP increased as TOC (total organic carbon) increased from Jan to Jun with exception of February. On temperature increase, THMFP values showed increase.
\end{abstract}

Keywords: Ganga, Trihalomethanes, Raw water, Anthropogenic, Seasonal variation

\section{Introduction}

Organic matter in natural water is considered the dominant THM precursor in drinking water $^{1}$. TOC concentration of water is generally an indication of the amount of THM precursor present ${ }^{2,3}$. Natural organic matter (NOM) is found in all water-surface, ground and soil. As a result of the interactions between the hydrological cycle, the biosphere and geosphere, the water sources used for drinking water purpose generally contain NOM. Thus the amount, character and properties of NOM differ considerably in water of different origins and depend on the biogeochemical cycles of the surrounding environments ${ }^{4}$. More ever, the range of organic components of NOM may also vary on the same location seasonally ${ }^{5}$. In addition to NOM, the sources of THM precursors may also be attributed to pollutant discharge, such as domestic sewage, industrial effluent, and agricultural drains ${ }^{6-8}$. Marhaba et al., ${ }^{9}$ used shrimp farm effluents from Bangpakong river in Thailand to determine their THMFP. They found that THMFP of the downstream was much higher as compared to that of the upstream and was due to contamination from shrimp farm effluents to the river. Chen et al., ${ }^{10}$ evaluated the impact of treated waste water discharge on downstream water 
quality in an effluent-dominated stream in the south-west USA. Lyon et al., ${ }^{11}$ studied the effect of inorganic precursors on disinfection by-product formation during UV-Chlorine/ Chloramine drinking water treatment. Recently, Gough et al., ${ }^{12}$ investigated the concentrations and characteristics of raw water dissolved organic carbon and THM formation potential. Most recently, Righi et al., ${ }^{13}$ measured THMs in the pool water samples and found interesting results.

Trihalomethanes are produced by reaction between available chlorine and organic substances in water as a result of the disinfection process. In addition, bromide ions in the water form Br-THMs. The most common formed THMs are chloroform, dichlorobromomethane, dibromochloromethane and bromoform. THM formation in chlorinated water was first identified by Bellar ${ }^{14}$ and Rook ${ }^{15}$. The occurrence of THMs in chlorinated water in India has been reported by Satyanaryana et al., ${ }^{16}$ and Thacker et al., ${ }^{17}$. Research has shown that people who regularly drink water containing a high level of chlorination by-products, especially bromine containing THMs, have a greater risk of developing bladder and rectal cancer than people who drink non-chlorinated water ${ }^{18,19}$. Several epidemiological studies have been carried out to establish the correlation between the chlorination of drinking water and cancer mortality ${ }^{20-25}$. There is evidence that dibromochloromethane is carcinogenic but that evidence is insufficient to access the human carcinogenic potential ${ }^{26}$. World Health Organization $^{27}$ has regulated the health related guideline values (GV) for THMs in drinking water (Table 1).

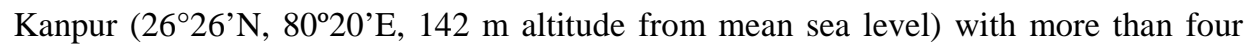
million population is an urban/ industrial site in the Indo-Gangetic basin in Northern India. Kanpur which was once known as the "Manchester of the East" is situated in the state of Uttar Pradesh on the banks of great Himalayan river Ganga. Literature review provides very scarce information regarding THM formation in Indian conditions. Kanpur has been chosen as the study site for analysing THMs in the surface raw water as this is the zone which is the hub of industrial activities and its dense population affect the water quality by discharging industrial effluents, domestic sewage and agricultural runoff in the river Ganges. The surface raw water samples were collected from Ganga Barrage Water Treatment Plant, Kanpur from January to June, 2009 to study the formation potentials of THMs due to anthropogenic sources and effect of various precursors on the potential of THM formation.

\section{Experimental}

All chemicals used were of the analytical reagent grade unless specified otherwise. High purity gas was used for various experimental purposes. De-ionized water obtained from a Milli-Q system (Millipore, USA) was used for all experimental purposes.

Pure compounds ( $>99 \%$ purity), viz., chloroform (CF), dichlorobromomethane (DCBM), dibromochloromethane (DBCM), bromoform (BF), 1-2 dibromopropane, trihalomethanes mix (200 ppm) were purchased from Sigma-Aldrich Ltd., USA. Potassium Iodide (99.8\% purity) was purchased from E.Merck (India) Pvt. Ltd., Bombay. Methyltertiary-butyl-ether (HPLC grade, $>99 \%$ purity), sodium sulfite (>98\% purity), anhydrous sodium sulfate (99.5\% purity) were purchased from Loba chemicals, India. The chemicals used for the DPD/FAS titration were anhydrous disodium hydrogen phosphate, anhydrous potassium dihydrogen phosphate, disodium ethylenediamine, tetraacetate dehydrate, mercuric chloride, $N, N$-diethyl-p-phenylenediamine, sulfuric acid, ferrous ammonium sulfate and sodium hypochlorite (4\%). All these chemicals were purchased from Loba chemicals, India. 


\section{Glassware}

Borosilicate glass (ASTM type-I, Wheaton Science, Millville, NJ, USA) vials of $40 \mathrm{~mL}$ equipped with screw caps having Teflon faced re-sealable septa were used. The $1 \mathrm{~L}$ capacity reagent bottles to preserve the chlorinated samples and $300 \mathrm{~mL}$ reagent bottles to quench the samples were also made of borosilicate glass. Micro syringes (Hamilton, USA) of $10 \mu \mathrm{L}$, $50 \mu \mathrm{L}, 100 \mu \mathrm{L}, 500 \mu \mathrm{L}$ and $1000 \mu \mathrm{L}$ were used during the experiments. The washing protocol for the vials involved rinsing with tap water to remove sample or solvent residues as the first step. Then the vials were kept overnight in a chromic acid bath. Next, the vials were washed thoroughly with phosphate free laboratory detergent and rinsed thoroughly with tap water and later rinsed with deionized (Milli-Q) water. After washing, the glassware were kept in an oven at $200{ }^{\circ} \mathrm{C}$ for drying, and later stored in a vacuum desiccator before final use. Re-usable septa were washed with phosphate free laboratory detergent and then thoroughly rinsed with tap water. Then they were rinsed with deionized water and kept in an oven at $60^{\circ} \mathrm{C}$ for $2-3 \mathrm{~h}$. Septa were stored in a vacuum desiccator before use in experiments. Clear $2 \mathrm{~mL}$ gas chromatograph (GC) auto sampler vials with $11 \mathrm{~mm}$ aluminum seals and PTFE rubber lined septa (Wheaton Science, USA) were used for sample storage for gas chromatographic (GC) analysis. These vials were used only once before disposal. All other glassware used in this study were also made of borosilicate glass, and purchased from Borosil, India. Before use, glassware were acid washed, followed by rinsing with tap water, distilled water and then dried in an oven at $180^{\circ} \mathrm{C}$.

\section{Surface water sample}

Surface raw water samples were collected from Ganga Barrage Water Treatment Plant, Kanpur (India) (capacity: $200 \mathrm{MLD}$ ) in sampling cans and carefully transported to the laboratory and were stored at $4{ }^{\circ} \mathrm{C}$.

\section{Sampling schedule}

Surface raw water samples were collected once in every month from January to June, 2009 in the first week of every month. Raw water samples were collected upstream of the treatment plant from river Ganges.

\section{Experimental procedure}

All the experiments were completed with utmost precaution and Standard Methods ${ }^{28}$ was referred to conduct experiments unless otherwise specified. In a typical experiment, surface raw water samples were chlorinated with 4 different chlorine doses each. The free chlorine residuals (FCR) and combined chlorine residuals (CCR) were measured for each sample and at each chlorine dose applied. THMs (4 compounds) concentrations were measured at 3 different contact times after chlorination. The formation potentials (FP) for the above compounds were measured 7 days after chlorination. UV absorbance@254 nm, bromide concentration and total organic carbon (TOC) were also measured for all water samples.

\section{Preliminary experiments}

Pure compounds (THMs and the internal standard) were diluted to required concentrations using MTBE. Five point calibration curves were prepared for GC for all the 4 THMs. All the curves were linear in nature. Extraction efficiencies for all the compounds were checked prior to the actual experiments and calibration curves were redrawn if recoveries were not found in the range of $90-110 \%$. Standard calibration curves were also prepared for TOC analyzer and Ion chromatograph (IC) to analyze total organic carbon and bromide concentration of water samples. 


\section{Chlorine application}

A stock solution of sodium hypochlorite $(1000 \mathrm{mg} / \mathrm{L})$ was prepared. As a preliminary exercise, raw water samples were chlorinated with different doses and the chlorine demand of the samples was determined using FAS/DPD titration method. Four dosages were finalized such that there was enough free chlorine residual after 30 min of chlorination. Four aliquots each of raw and treated water were taken in $1 \mathrm{~L}$ capacity reagent bottles. Hypochlorite solution was added to these bottles to achieve the required chlorine concentration. The bottle contents were mixed and stored at $20^{\circ} \mathrm{C}$. Chlorine residuals (FCR, CCR) were measured after 30 min of chlorination using FAS/DPD titration.

\section{Extraction of disinfection by- products}

Samples were extracted in duplicate for THM determination. For a typical extraction, after specified contact time, a $50 \mathrm{~mL}$ aliquot was used. Sodium sulfite was added to the aliquot to quench the available free chlorine before extraction. EPA method 551.1 was adapted for extraction of THMs. Liquid-liquid extraction method has been used for the determination of THMs in aqueous samples. This method is also known as solvent extraction and partitioning, it is used to separate compounds based on their relative solubility in two different immiscible liquids, usually water and an organic solvent. It is extraction of a substance from one liquid phase into another liquid phase. This is the separation of a substance from a mixture by preferentially dissolving that substance in a suitable solvent. For the extraction of THMs, $20 \mathrm{~mL}$ quenched aliquot was taken in a $40 \mathrm{~mL}$ glass vial and $3 \mathrm{~mL}$ MTBE was added followed by $8 \mathrm{~g}$ sodium sulfate. For proper mixing, the vial was kept in a secure horizontal position for some time with the undissolved sodium sulfate distributed along the length of the vial. $1 \mathrm{~mL}$ of the upper organic layer was taken into $2 \mathrm{~mL}$ GC vial and $10 \mu \mathrm{L}$ of Internal Standard (10 ppm, 1-2 dibromopropane) was added by using a $50 \mu \mathrm{L}$ syringe. All chromatographic analyses were performed using a Gas Chromatograph equipped with an electron capture detector (Model: 910, Buck Scientific, USA). A packed column (Resteck MS-5A 100/120 10ft 2 mm ID $1 / 8^{\text {th }}$ in OD, SILCO SRI 8610C) was used. Samples were extracted from GC auto sampler vials using a micro syringe. Injection volume was $1 \mu \mathrm{L}$ in all cases. High purity (zero grade) Helium and Nitrogen were used as the carrier and make up gases respectively. Carrier and make up gas flow were about $30 \mathrm{~mL} \mathrm{~min}^{-1}$ and $60 \mathrm{~mL} \mathrm{~min}^{-1}$ respectively. The concentration of dissolved organic carbon was detected with a TOC analyzer (Model: TOC-5000A, Shimadzu, Japan). The $\mathrm{pH}$ of water samples was measured using a combination $\mathrm{pH}$ electrode (Toshniwal CL-51, India) connected to a digital $\mathrm{pH}$ meter (Toshniwal CL-54, India). The alkalinity was deduced from inorganic carbon and $\mathrm{pH}$ values of the water samples. The concentration of bromide ion was measured by ion chromatograph (Model: 761 compact IC, Met Rohm, USA). UV absorbance at $254 \mathrm{~nm}$ $\left(\mathrm{UV}_{254}\right)$ was measured with a spectrophotometer (UV-VIS, Varian, USA).

\section{Results and Discussion}

The various water quality parameters measured in each sample are tabulated in Table 2 .

The collected surface raw water samples were chlorinated at various dosages and corresponding free chlorine residual (FCR) and combined chlorine residual(CCR) values were measured. FCR and CCR plots for surface raw water are shown in Figure 1. Further, concentrations of various THM species in the said water samples were determined at different times corresponding to each chlorine dose. 
Table 1. Guideline values for drinking water quality ${ }^{27}$

\begin{tabular}{ccc}
\hline Disinfection by-products & Guideline Values, $\mu \mathrm{g} / \mathrm{L}$ & Remarks \\
\hline Trihalomethanes & - & $\begin{array}{c}\text { The sum of the ratio of the } \\
\text { concentration of each to its } \\
\text { respective guideline value } \\
\text { should not exceed } 1\end{array}$ \\
Bromoform & 100 & \\
Chlorodibromomethane & 100 & \\
Bromodichloromethane & 60 & \\
Chloroform & 300 & \\
\hline
\end{tabular}

Table 2. Raw Ganga water quality parameters

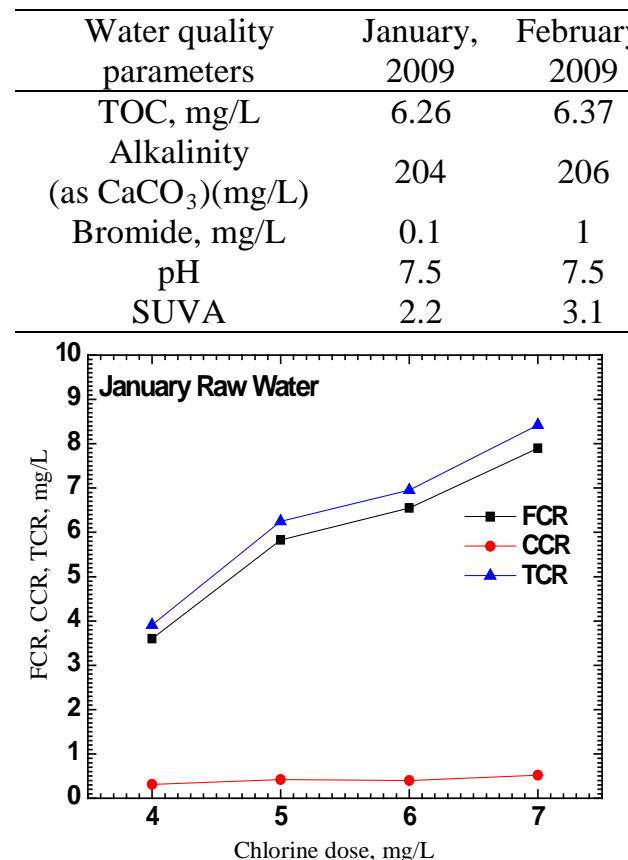

March, April, May, June, 

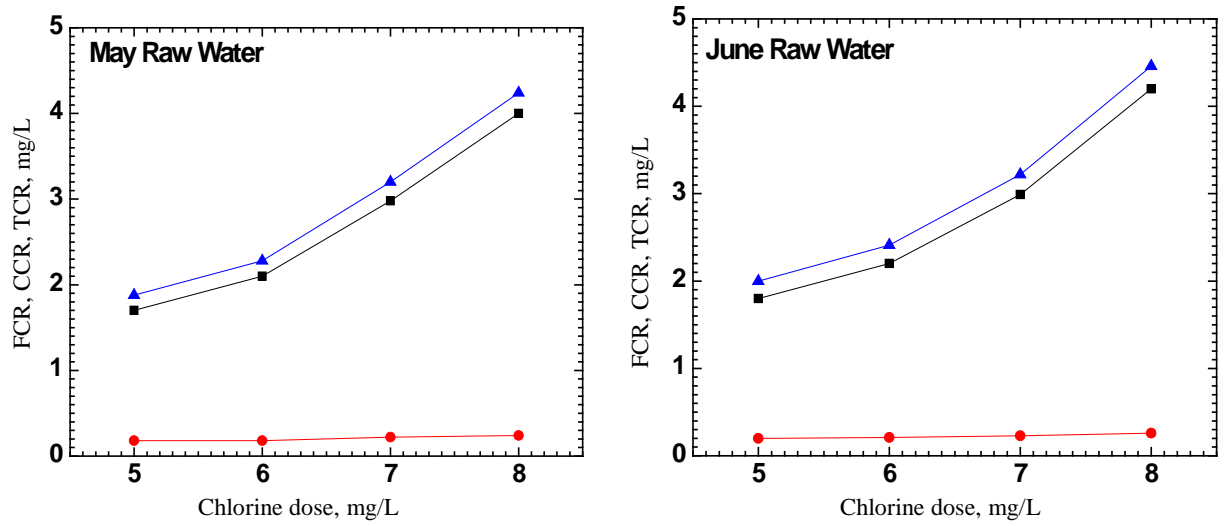

Figure 1. FCR, CCR and TCR values for surface raw water for different chlorine doses from January to June, 2009

\section{Trihalomethane formation potential}

In the surface raw water samples collected from January to June, 2009, the THMFP values at $5 \mathrm{mg} / \mathrm{L}$ chlorine dose were $77.64,174.98,139.32,202.5,218.9$ and $235.7 \mu \mathrm{g} / \mathrm{L}$, respectively. CF, DBCM, DCBM, and BF were identified (except in January where DCBM and $\mathrm{BF}$ were absent) and their concentrations are shown in Figure 2(a). All the concentrations were below the WHO guideline values. The THMFP values at $6 \mathrm{mg} / \mathrm{L}$ chlorine dose from January to June were: 96.4, 197.54, 152.2, 234.99, 250.6 and $263.3 \mu \mathrm{g} / \mathrm{L}$, respectively. CF, DCBM, DBCM and BF were identified except in January where DCBM and $\mathrm{BF}$ were absent and their concentrations were shown in Figure 2(b). All the concentrations were below WHO GV. The THMFP values at $7 \mathrm{mg} / \mathrm{L}$ chlorine dose from January to June were $135.7,214.85,193.7,267.21,283.1$ and $300 \mu \mathrm{g} / \mathrm{L}$, respectively. The CF, DCBM, DBCM and BF were identified except in January where only CF and DCBM were present Figure 2(c). All the values were below the WHO GV.

\section{Seasonal variations in THMFP}

THMFP values in May and June were found to be three times higher than those in January (Figure 3$)^{29}$. There is abrupt rise in the values of THMFP in the month of February. This might be because of the rapid decay of vegetation (a source of NOM in water) during spring $^{30}$. Among individual THM species in surface raw water, the chloroform levels were found higher than DCBM, DBCM and bromoform in all the seasons Figure 2(a,b.c) .

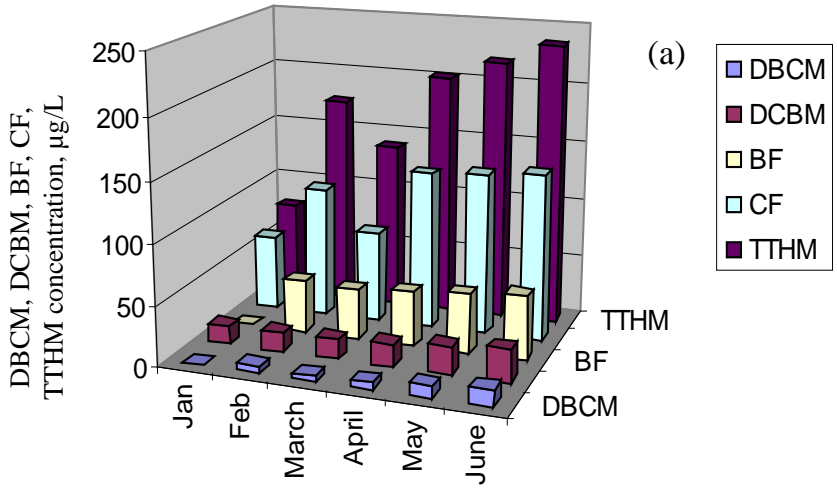



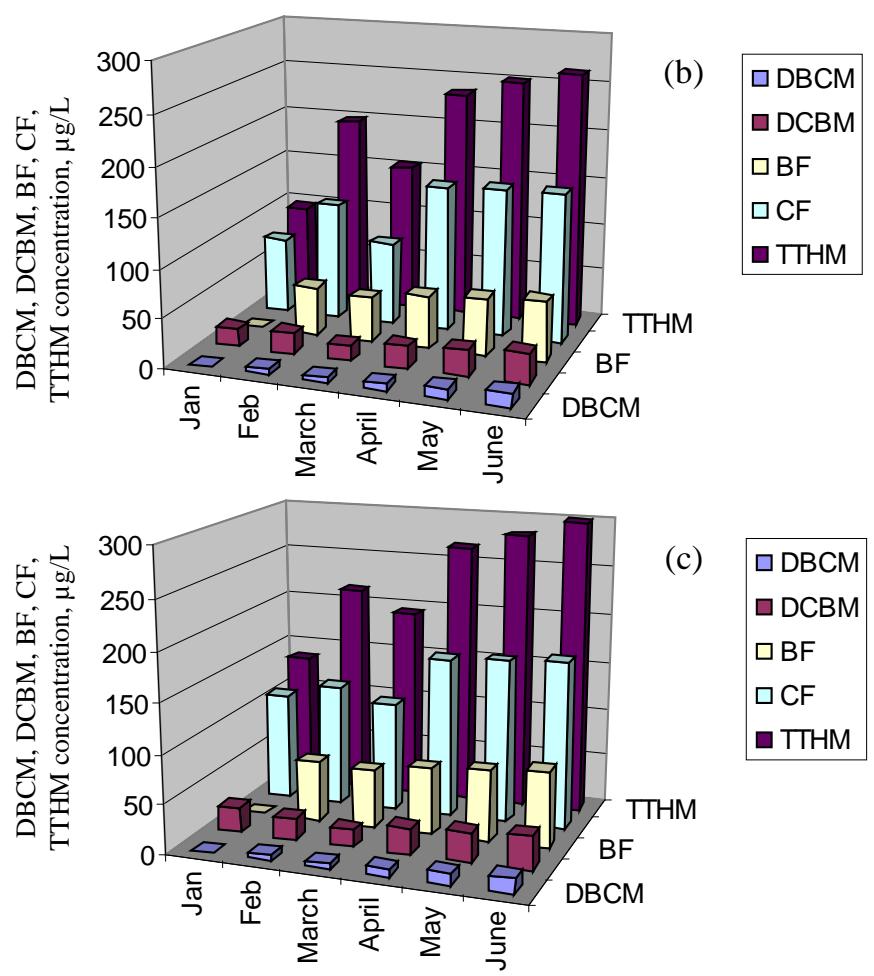

Figure 2. Temporal variations of the THMs concentrations in surface raw water for different chlorine doses (a) $5 \mathrm{mg} / \mathrm{L}$ (b) $6 \mathrm{mg} / \mathrm{L} \mathrm{(c)} 7 \mathrm{mg} / \mathrm{L}$.

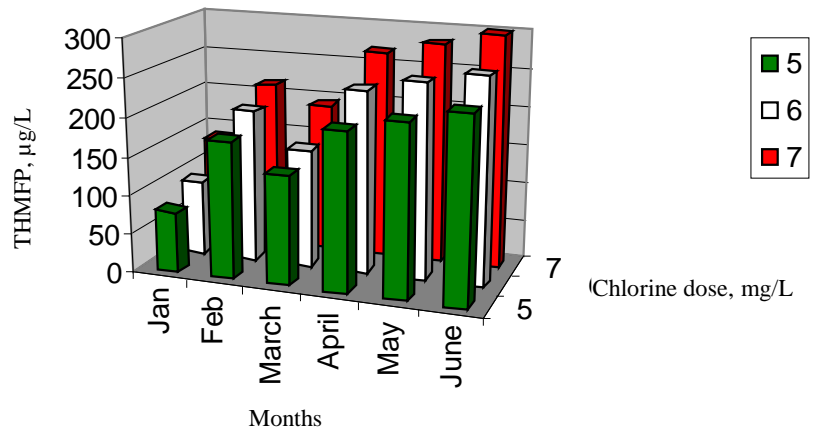

Figure 3. Seasonal variation in THMFP in surface raw water at different chlorine doses

\section{Relationship between Reaction time and THMFP}

Investigation was conducted to examine the relationship between the varying reaction time $(\mathrm{t}=4,8,24,168 \mathrm{~h} ; 168 \mathrm{~h}$ reaction time represents the Formation Potential) with varying chlorine dosages with the THM formation in the surface raw water samples collected from Jan. to Jun., 2009. The investigation illustrated that the THM formation rate was found to be very fast in first $24 \mathrm{~h}$ compared to that of exceeding reaction time ( $>24 \mathrm{~h}$ ) (Figure 4 to 9). The higher the reaction time leads to the higher THM concentration which is very prominent at higher chlorine dosages. The concentrations of BF, DCBM and DBCM were nearly 
independent of reaction time when it was more than $24 \mathrm{~h}$ for each considered chlorine dose. The higher the reaction time leads to the higher chloroform concentration which is very prominent for higher chlorine dosages. DCBM showed nearly negligible growth with higher reaction time with increasing chlorine dosages (Figure 4 to 9). The THMFP values showed increasing pattern with higher chlorine dosages (Figure 4 to 9).
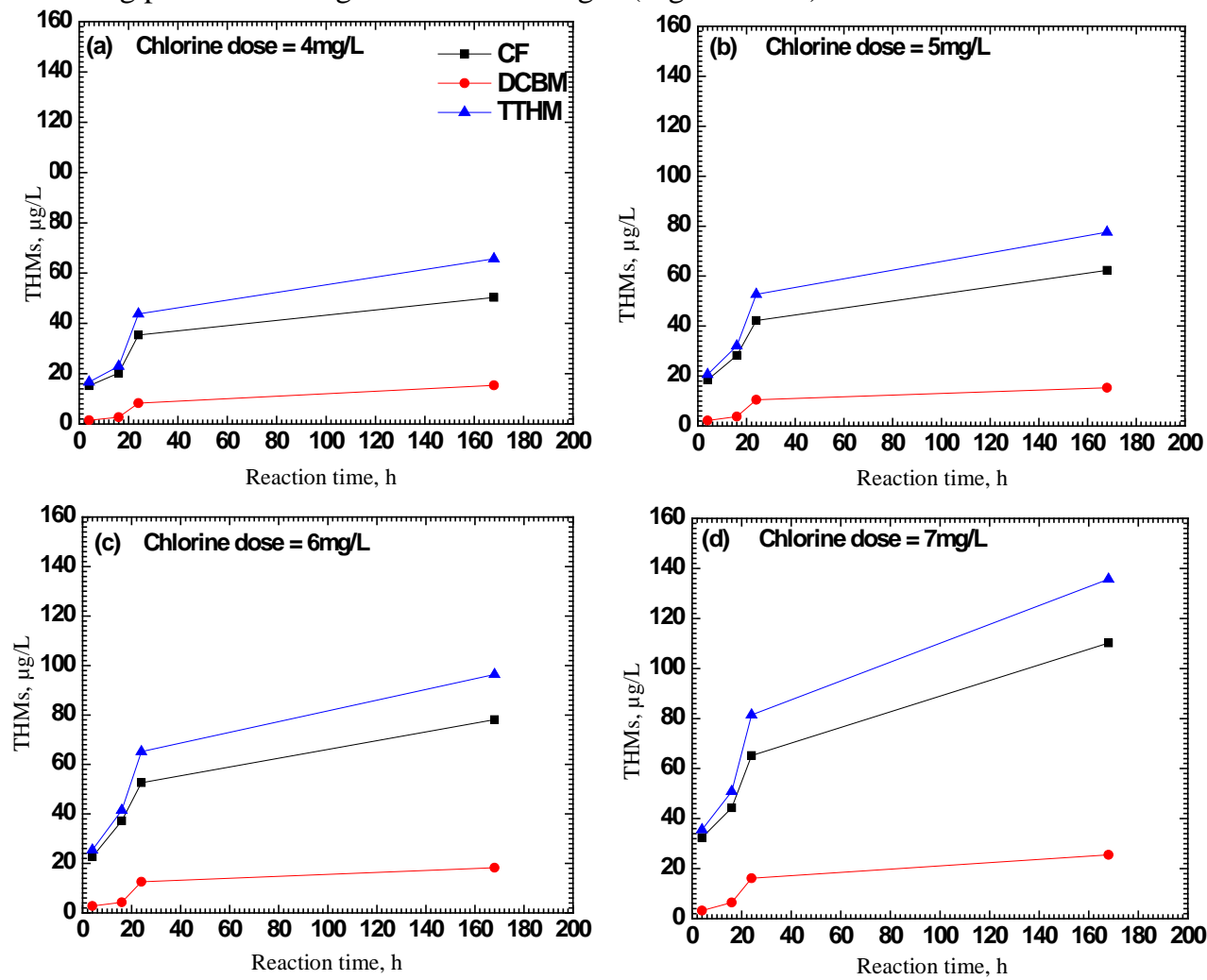

Figure 4. Effect of reaction time on THMs formation at different chlorine doses in the raw water sample collected from Ganga barrage Water Treatment Plant, Kanpur in January 2009
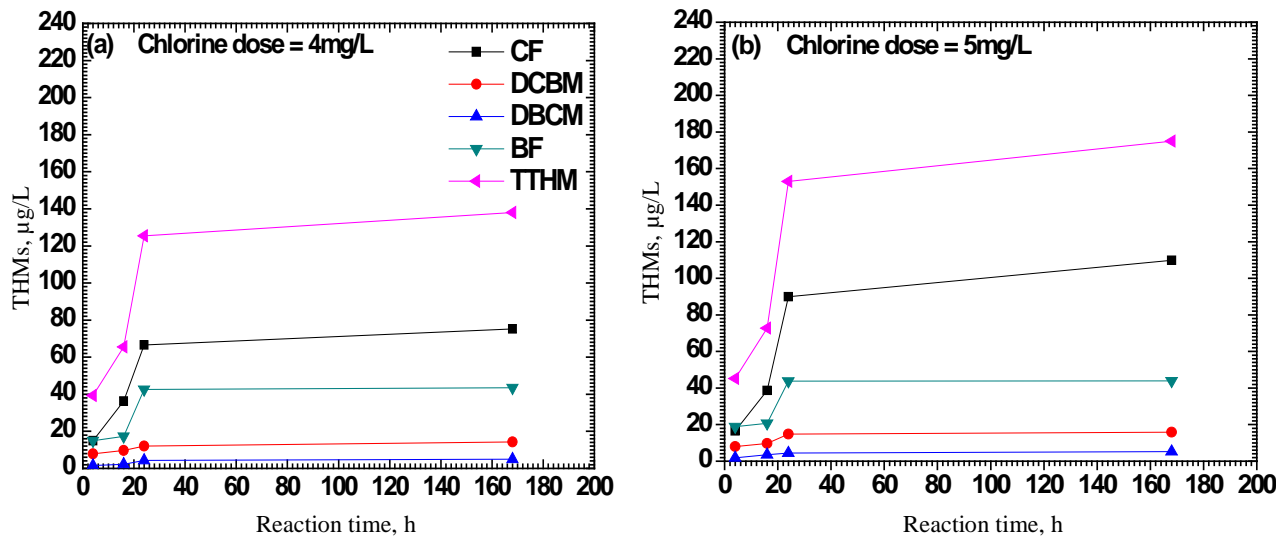

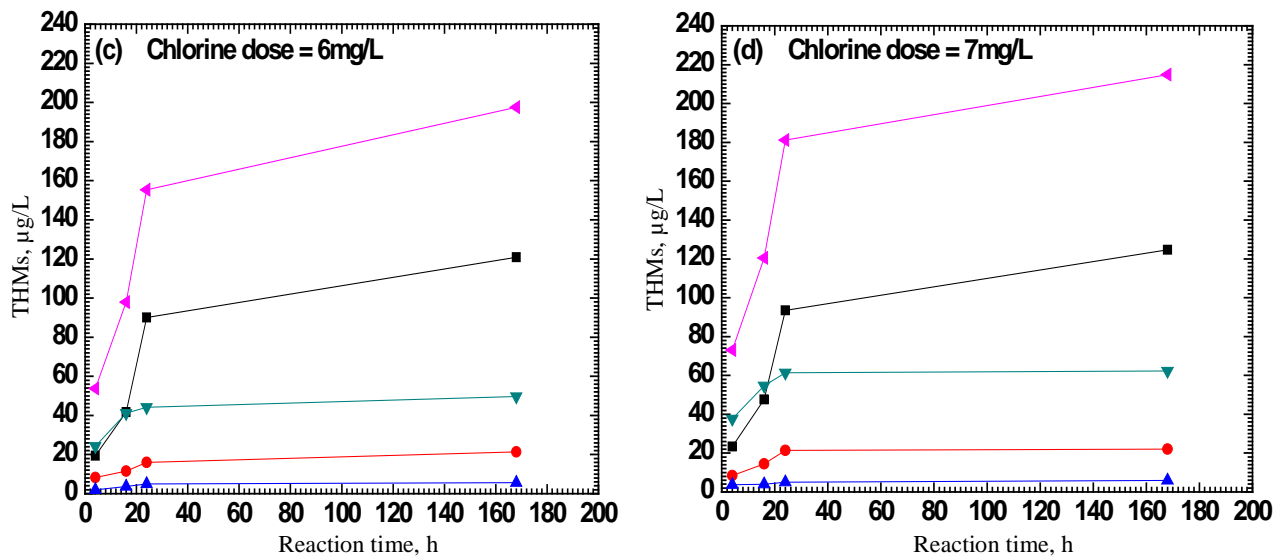

Figure 5. Effect of reaction time on THMs formation at different chlorine doses in the raw water sample collected from Ganga barrage Water Treatment Plant, Kanpur in February, 2009
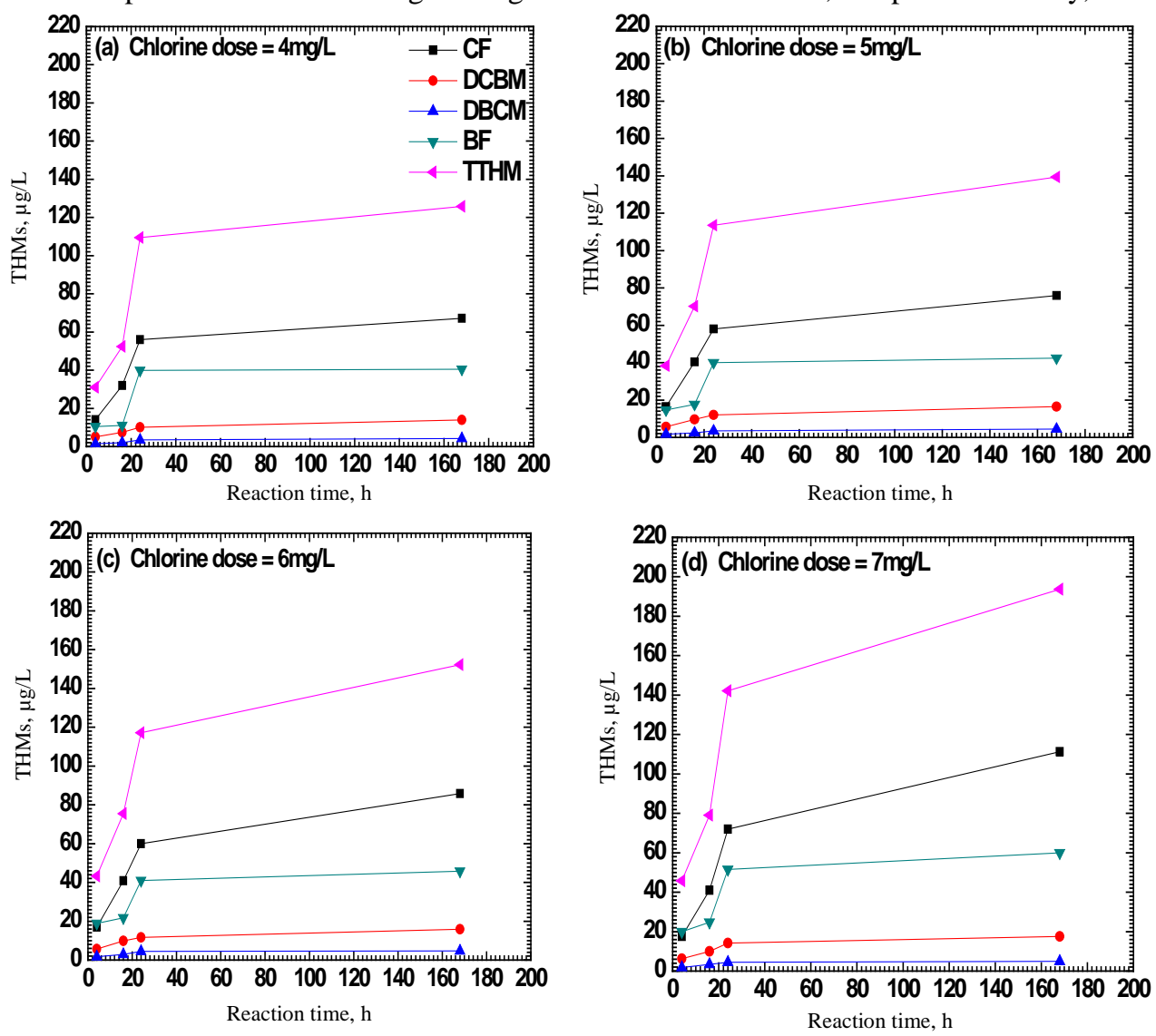

Figure 6. Effect of reaction time on THMs formation at different chlorine doses in the raw water sample collected from Ganga barrage Water Treatment Plant, Kanpur in March, 2009 

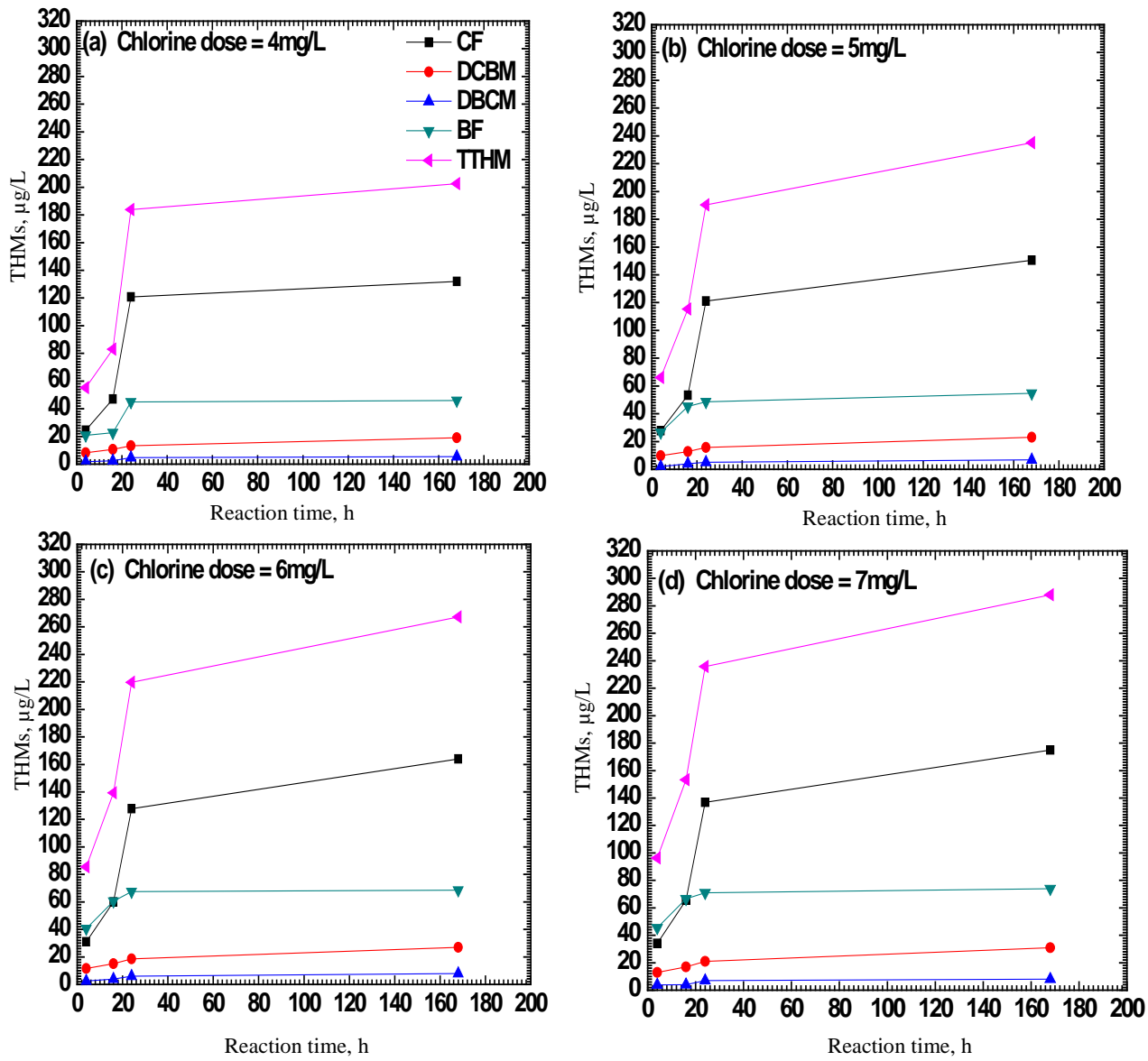

Figure 7. Effect of reaction time on THMs formation at different chlorine doses in the raw water sample collected from Ganga barrage Water Treatment Plant, Kanpur in April, 2009
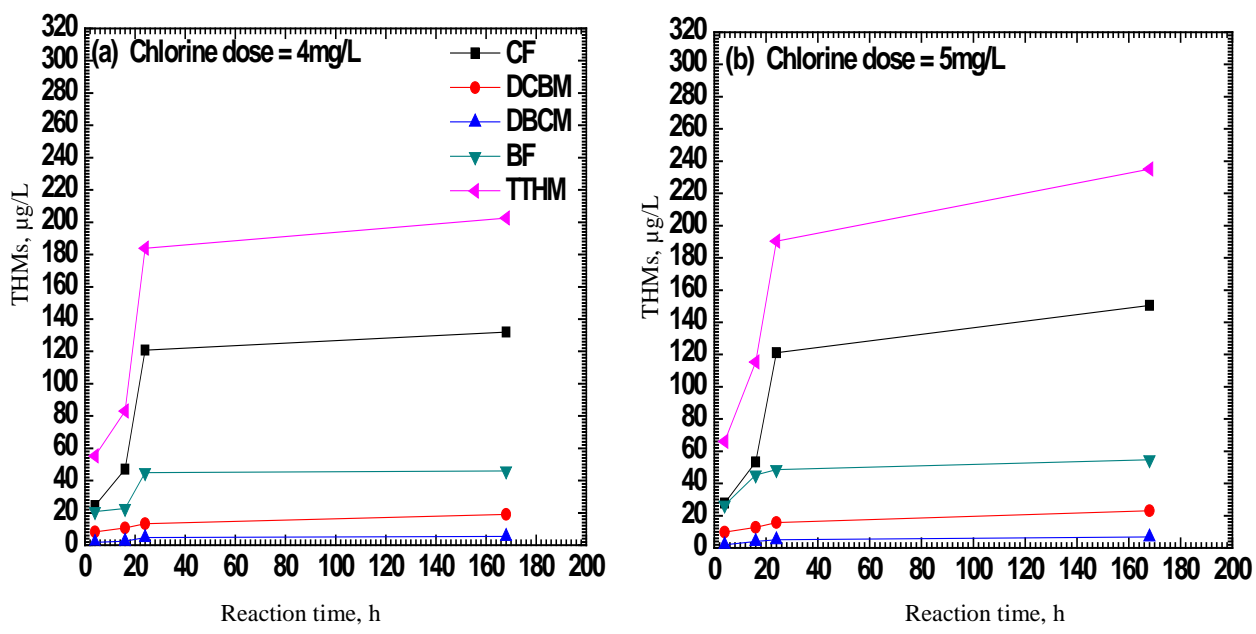

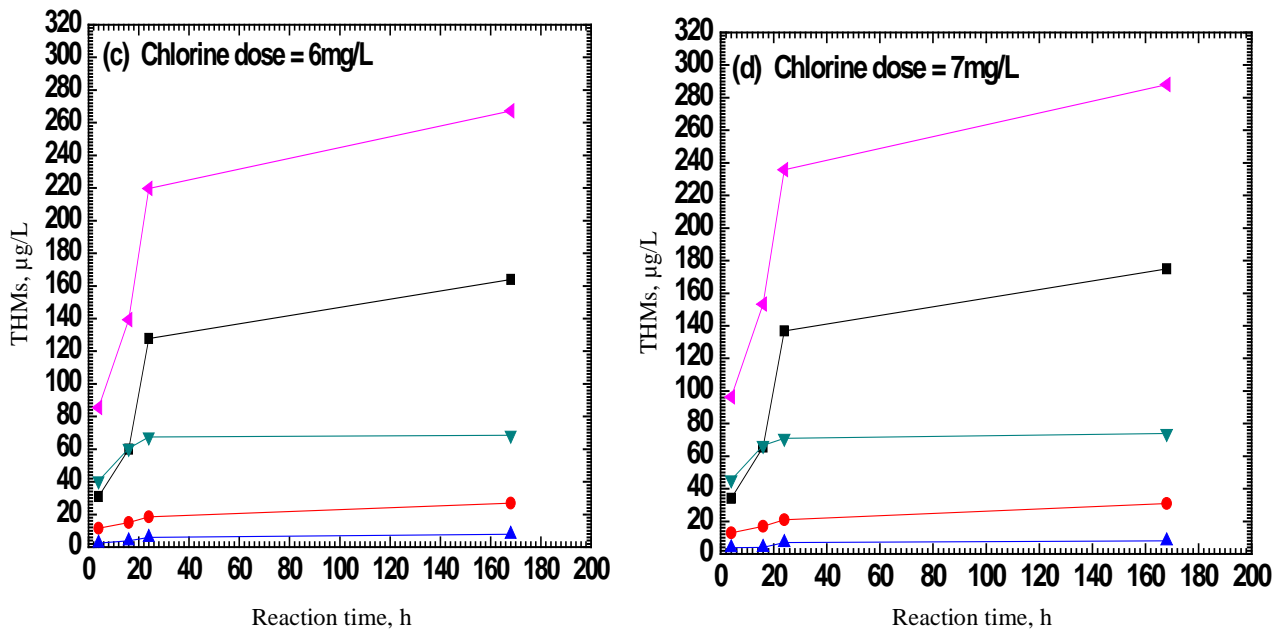

Figure 8. Effect of reaction time on THMs formation at different chlorine doses in the raw water sample collected from Ganga barrage Water Treatment Plant, Kanpur in May, 2009
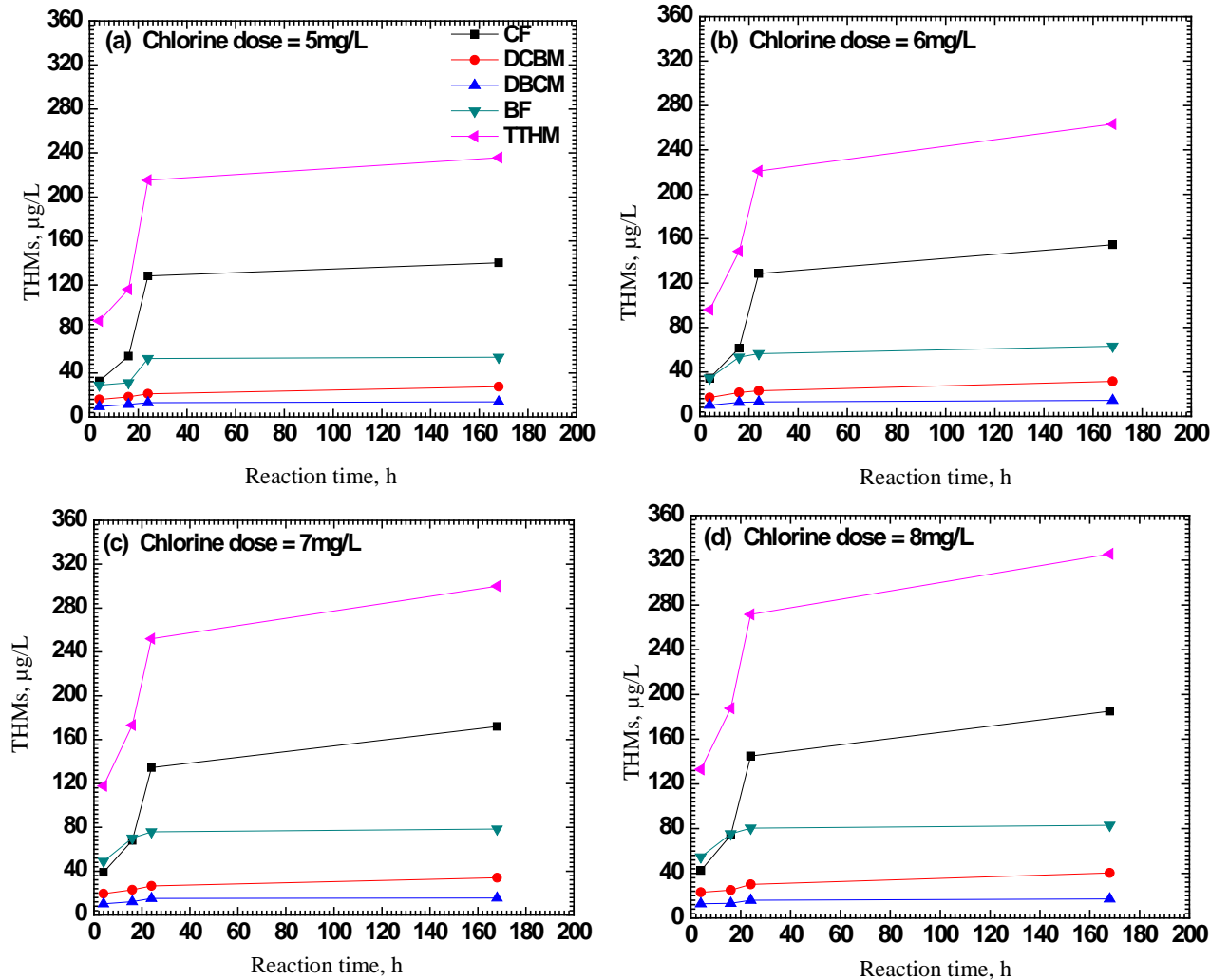

Figure 9. Effect of reaction time on THMs formation at different chlorine doses in the raw water sample collected from Ganga barrage Water Treatment Plant, Kanpur in June, 2009 


\section{Temporal variation of THMFP}

The values of THMFP showed the ascending trend from January to June with the exception of February (Figure 2a,b,c).The above pattern supports the theme that temperature enhances the THMFP concentration. The exceptionally high THMFP value in February might be attributed to rapid decay of vegetation (a source of NOM in water) during spring

\section{Effect of Bromide concentration on THMFP}

At different chlorine dosages (5 mg/L, $6 \mathrm{mg} / \mathrm{L}$ and $7 \mathrm{mg} / \mathrm{L}$ ) all the THMs were formed except in the month of January in which only chloroform and dichlorobromomethane (DCBM) were formed.

\section{Effect of Chlorine dosages on THMFP}

It was observed that as the chlorine dosages increased, the values of the THMFP also increased (Figure 3), with the exception of February which showed the abrupt rise.

\section{Effect of Total organic carbon (TOC) on THMFP}

It was observed that with the increase in the chlorine dose, the values of THMFP increased as the TOC increased from Jan. to Jun, 2009 with the exception of February which showed abrupt elevation in THMFP value (Figure 10). In the month of February, there is rapid decay of vegetation (a source of NOM in water) during spring. Due to increased TOC, the value of THMFP might have elevated.

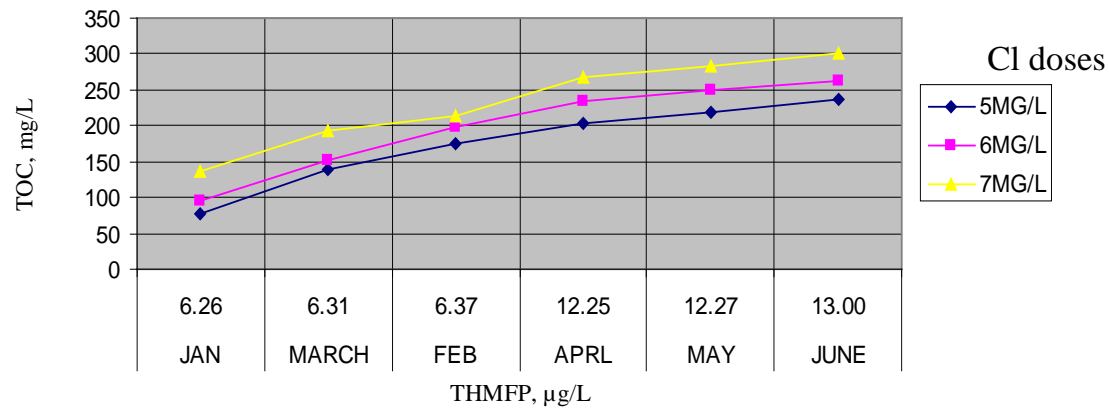

Figure 10. The Effect of TOC on THMFP in surface water at different chlorine dosages

\section{Relationship between Temperature and THMFP}

Surface raw water sample collected in Feb. 2009 was studied for temperature sensitivity on the THM species formation at different reaction times $(\mathrm{t}=4,16,24$ and $168 \mathrm{~h})$ at $6 \mathrm{mg} / \mathrm{L}$ chlorine dosage. It was observed that when the temperature was increased from $20^{\circ}$ to $30^{\circ}$, there was slight increase except in the case of DBCM formation which at 16 and $24 \mathrm{~h}$ showed more formation as compared to other THMs (Figure 11). THMFP (168 h.) values showed little increase when the temperature was increased from $20^{\circ}$ to $30^{\circ} \mathrm{C}$ (Figure 11).

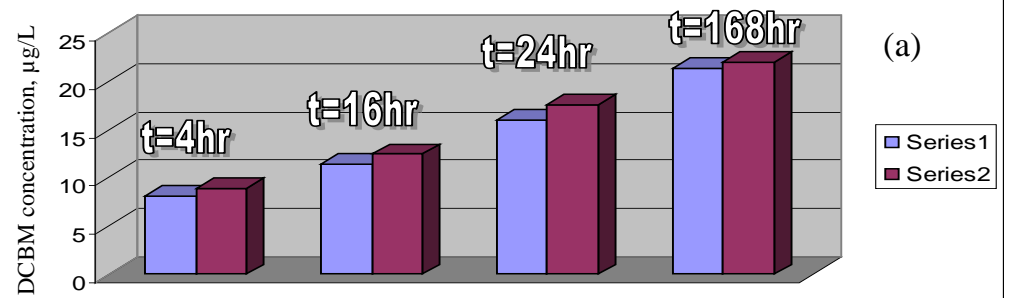



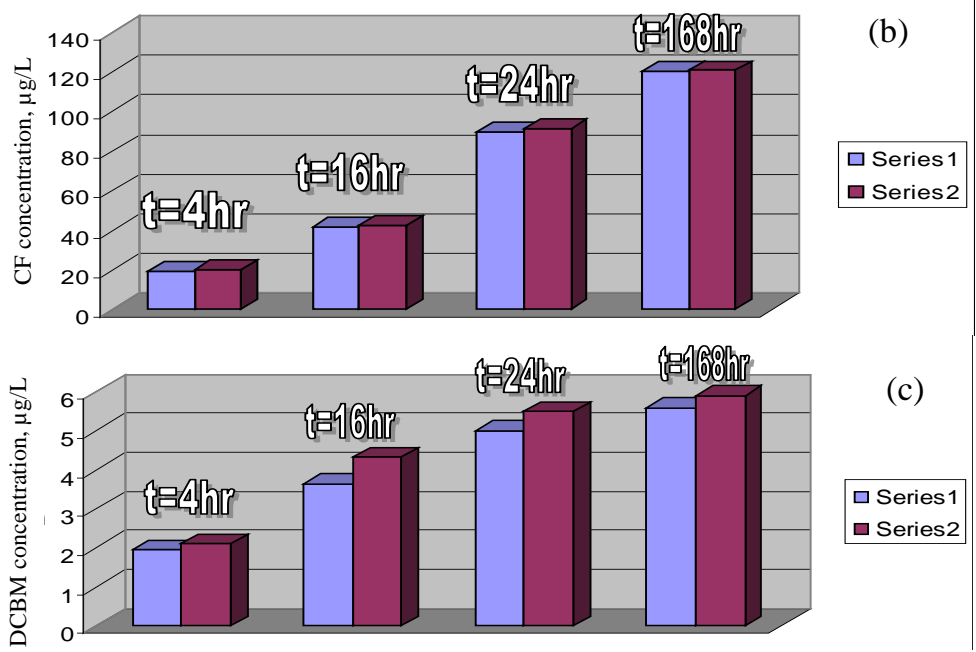

(d)
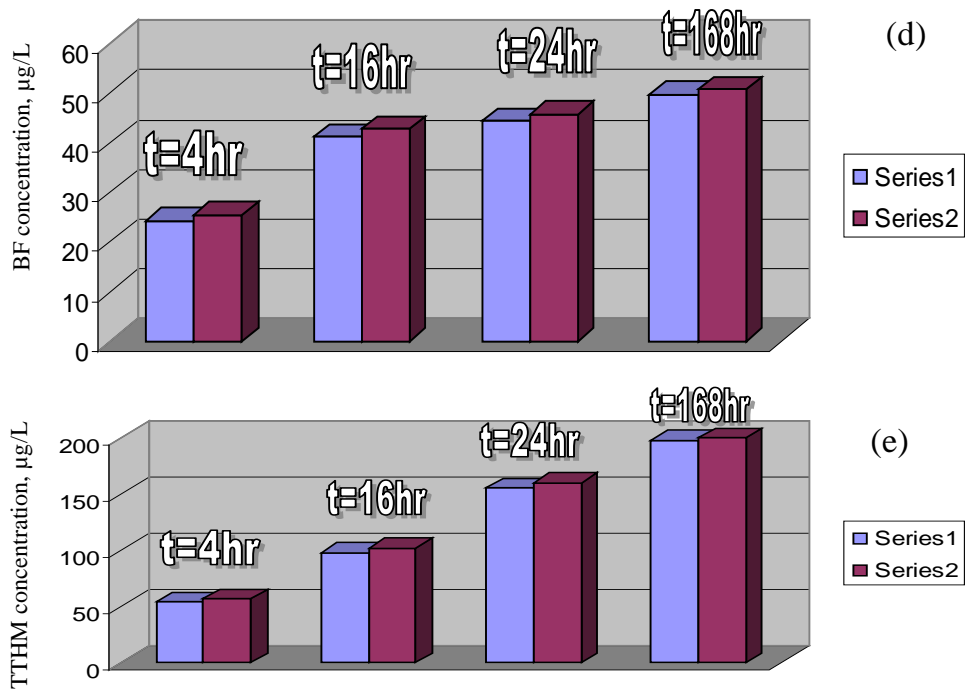

Figure 11. The temperature sensitivity of the THM species formation with varying reaction time. Series 1 and Series 2 correspond to the THM species formation at temperature 20 and $30{ }^{\circ} \mathrm{C}$ respectively

\section{Conclusion}

In the surface raw water samples, the concentrations of THMs and THMFP at different chlorine dosages were below the WHO GV. Trihalomethane formation potential (THMFP) values in May and June were found to be three times higher than those in Jan. Among individual THM species, the chloroform levels were found higher than DCBM, DBCM, and $\mathrm{BF}$ in all the seasons. The seasonal variation of chloroform concentrations reported the levels lower than the WHO GV. In the investigation to examine the relationship between the varying reaction time and varying chlorine dosages, it was observed that the THM formation rate was found to be very fast in first $24 \mathrm{~h}$ compared to that of exceeding reaction time ( $>24 \mathrm{~h}$.). The higher the reaction time leads to the higher THM concentrations which was very prominent 
at higher chlorine dosages. The concentrations of BF, DCBM, and DBCM were nearly independent of reaction time when it was more than $24 \mathrm{~h}$ for each considered chlorine dosages. The DCBM showed nearly negligible growth with higher reaction time with increasing chlorine dosages. The values of THMFP showed the ascending trend from Jan. to June with the exception of Feb. which proved that increased temperature enhances the THMFP concentrations. Presence of bromide in raw water could significantly increase its THMFP. With the increase in the chlorine dosages, the values of THMFP increased as the TOC increased from Jan. to June with the exception of Feb. It was observed that when the temperature was increased from $20^{\circ}$ to $30{ }^{\circ} \mathrm{C}$, there was slight increase except in the case of DBCM formation which at 16 \& $24 \mathrm{~h}$ showed more formation as compared to other THMs. THMFP (168 h) values showed increase when the temperature was increased from $20^{\circ}$ to $30^{\circ} \mathrm{C}$.

\section{Acknowledgement}

One of the authors, NDM is sincerely acknowledging the assistance given by Dr. N.P. Thacker, a luminary at NEERI, Nagpur (India) in the form of advice, help and valuable guidance whenever required. NDM is also thankful to the staff of the Ganga Barrage Water Treatment Plant, Kanpur (India) for assisting in the collection of water samples.

\section{References}

1. Collins M R, Amy G L and King P H, J Environ Engg., 1985,111(6), 850-864.

2. Urano K, Wada H and Takemasa T, Water Res., 1983, 17(12), 1797-1802; DOI:10.1016/0043-1354(83)90202-6

3. Galapate R P, Kitanaka A, Ito K, Tetsuo M, Eiji S and Okada M, Water Sci Tech., 1997, 35(8), 15-20; DOI:10.1016/S0273-1223(97)00146-7

4. Fabris R, Chow C W K, Drikas M and Eikebrokk B, Water Res., 2008, 42(15), 41884196; DOI:10.1016/j.watres.2008.06.023

5. Sharp E I, Parsons S A and Jefferson B, Sci Total Environ., 2006, 363(1-3), 183-194; DOI:10.1016/j.scitotenv.2005.05.032

6. Chu H P and Li X Y, NOM characterization: molecular weight and trihalomethane formation potentials. In: Proceedings of 1st World Congress of the International Water Association, Paris, France, 3-7 July, 2000.

7. Galapate R P, Baes A V, Ito K, Iwase K and Okada M, Water Res., 1999, 33(11), 2555-2560; DOI:10.1016/S0043-1354(98)00481-3

8. Rebhun M, Heller-Grossman L and Manka J, Water Environ Res., 1997, 69(6), 11541162; DOI:10.2175/106143097X125902

9. Marhaba T F, Mangmeechai A, Chaiwarpongsakorn C and Pavasant P, J Hazard Mat., 2006, 136(2), 151-163; DOI:10.1016/j.jhazmat.2005.12.011

10. Chen B, Nam N S, Westerhoff P K, Krasner S W and Amy G, Water Res., 2009, 43(6), 1755-1765; DOI:10.1016/j.watres.2009.01.020

11. Lyon B A, Dotson A D, Linden K G and Weinberg H S, Water Res., 2012, 46(15), 4653-4664; DOI:10.1016/j.watres.2012.06.011

12. Gough R, Holliman P J, Willis N and Freeman C, Sci Total Environ., 2014, 468-469, 228-239; DOI:10.1016/j.scitotenv.2013.08.048

13. Righi E, Fantuzzi G, Predieri G and Aggazzotti G, Microchem J., 2014, 113, 23-29; http://dx.doi.org/DOI:10.1016/j.microc.2013.11.007

14. Bellar T, Lightenburg J and Kroner R, J Am Water Works Assoc., 1974, 66, 703-706.

15. Rook J J, J Am Water Works Assoc., 1976, 68(3), 168-172.

16. Satyanarayana M and Chandrashekhar M, Indian J Environ Prot., 1996, 16(6), 423-426. 
17. Thacker N P, Kaur P and Rudra A, Environ Edu Inf., 1997, 16(4), 367-376.

18. Boorman G A, Dellarco V, Dunnick J K, Chapin R E and Huner S, Hauchman F, Gardner H and Cox M R C, Environ Health Perspect Suppl., 1999, 107(2), $207-217$.

19. Fawell J, Food Chem Toxicol., 2000, 38(Suppl), S91-S95.

20. Flaten T P, Int J Epidemiol., 1992, 21(1), 6-15; DOI:10.1093/ije/21.1.6

21. Morris R D, Environ Health Perspect., 1995, 103(8), 225-231.

22. Pilotto L S, Aust J Pub Health., 1995, 19(1), 89-93.

23. Gallagher M D, Nuckols J R, Stallones and Savitz D A, Epidemiol., 1998, 9(5), 484-489.

24. Yang C Y, Chiu H F, Chang M F and Tsai S S, Environ Res., 1998, 78(1), 1-6; DOI:10.1006/enrs.1997.3823

25. Yang C Y, Cheng B H, Tsai S S, Wu T N, Lin M C and Lin K C, Environ Health Perspect., 2000, 108(8), 765-768.

26. US, EPA. Guidelines for water reuse. EPA/625/R-04/108, Sept, 2004.

27. WHO Guidelines for drinking water quality, $4^{\text {th }}$ Ed., 2011, World Health Organization, Geneva.

28. American Public Health Association (APHA) Standard methods for the examination of water and wastewater. 1998, 20.

29. Dojilido J, Zbiec E D and Swietlik R, Water Res., 1999, 33(14), 3111-3118; DOI:10.1016/S0043-1354(99)00030-5

30. Rodriguez M J, Serodes J and Levallois P, Water Res., 2004, 38(20), 4367-4382; DOI:10.1016/j.watres.2004.08.018 